\title{
ANALISIS PERBANDINGAN KINERJA LOAD BALANCING METODE ECMP (EQUAL COST MULTI-PATH) DENGAN METODE PCC (PER CONNECTION CLASSIFIER) PADA MIKROTIK ROUTEROS
}

\author{
Fakultas Teknologi Informasi \\ Universitas Islam Kalimantan Muhammad Arsyad Al Banjari Banjarmasin \\ Muhammad Iqbal Firdaus \\ email: m.iqbalfirdaus@uniska-bjm.ac.id.com
}

\begin{abstract}
Salah satu solusi untuk mendapatkan kualitas layanan internet yang lebih baik adalah dengan memanfaatkan teknologi load balancing. Banyaknya penyedia layanan internet di Indonesia memberikan kita banyak pilihan operator mana yang akan kita gunakan layanannya. Kita dapat menggunakan lebih dari satu koneksi internet dari penyedia layanan internet yang berbeda yang kemudian di seimbangkan dengan teknologi Load Balancing. Load balancing metode ECMP (Equal Cost Muli Path) dan Metode PCC (Per Connection Classifier) merupakan contoh metode load balancing yang sering diterapkan pada jaringan komputer. Permasalahan yang kita hadapi adalah, diantara meode load balancing tersebut masing-masing mempunyai beberapa kelebihan dan kekurangan
\end{abstract}

Kata kunci: Load balancing, ECMP, PCC, qos

\section{PENDAhUluan Pendahuluan}

Salah satu solusi untuk mendapatkan kualitas layanan internet yang lebih baik adalah dengan memanfaatkan teknologi load balancing. Banyaknya penyedia layanan internet di Indonesia memberikan kita banyak pilihan operator mana yang akan kita gunakan layanannya. Kita dapat menggunakan lebih dari satu koneksi internet dari penyedia layanan internet yang berbeda yang kemudian di seimbangkan dengan teknologi load balancing.

Teknologi load balancing ini sudah banyak didukung pada berbagai sistem. Salah satunya adalah pada sistem MikroTik RouterOS. MikroTik, baik RouterBoard maupun RouterOS, banyak digunakan di Indonesia contohnya pada UKM (Usaha Kecil dan Menengah) dan juga pada pengguna perorangan, karena Jurnal Ilmiah "Technologia" harganya yang lebih terjangkau tetapi dapat menyediakan kinerja yang cukup memadai.

Pada MikroTik RouterOS itu sendiri dapat dijumpai berbagai metode load balancing yang bisa kita pilih, diantaranya adalah metode ECMP (Equal Cost MultiPath) dan metode PCC (Per Connection Classifier). Kedua metode diatas mempunyai karakteristik yang sama, dimana keduanya mendukung penyebaran traffic data pada setiap koneksi maupun setiap paket data. Diantara kedua metode load balancing tersebut pasti mempunyai kekurangan dan kelebihan masingmasing. Penelitian ini bertujuan untuk mengetahui metode mana yang mempunyai kinerja lebih baik.

\section{Tujuan Kegiatan}


Tujuan dari penelitian ini adalah menemukan kelebihan dan kekurangan dari kinerja load balancing metode ECMP dan PCC, sehingga dapat menentukan usaha selanjutnya untuk mendapatkan kualitas layanan internet yang lebih baik.

\section{TINJAUAN PUSTAKA}

\section{Load Balancing}

Load balancing dapat diartikan sebagai suatu metode untuk menyebarkan beban kerja lalu lintas data secara seimbang melalui beberapa perantara untuk mengoptimalkan penggunaan sumber daya yang ada sehingga didapatkan kinerja yang lebih baik.

Load balancing pada mikrotik adalah teknik untuk mendistribusikan beban lalu lintas data pada dua atau lebih jalur koneksi secara seimbang, agar traffic dapat berjalan optimal, memaksimalkan throughput, memperkecil waktu tanggap dan menghindari overload pada salah satu jalur koneksi (Dewobroto, 2012).

\section{ECMP (Equal Cost Multi-Path) Load Balancing}

ECMP merupakan suatu teknik routing untuk mengatur rute paket melalui beberapa jalur yang yang mempunyai nilai sama. Engine yang bertugas mengirimkan paket mengidetifikasi jalur berdasarkan hop berikutnya (Hopps, 2000). Semua jalur diantara tiap-tiap node mempunyai nilai routing yang sama, sehingga lalu lintas data akan dibagi sama rata.

\section{PCC (Per Connection Classifier) Load Balancing}

PCC adalah salah satu metode load balancing pada router mikrotik yang memungkinkan pengguna untuk membagi lalu lintas data menjadi aliran data yang sama besar dan mampu menjaga paket

Jurnal Ilmiah "Technologia” dengan serangkaian aturan pada aliran data tertentu (MikroTik, 2008).

\section{MikroTik RouterOS}

Perangkat routerMikrotik RouterOS merupakan sebuah sistem operasi yang fiturnya sudah dioptimalisasi untuk menyediakan fungsi-fungsi sebuah router. Mikrotik routeros adalah versi mikrotik dalam bentuk perangkat lunak yang dapat diinstall pada komputer rumahan PC (Personal Computer) melalui CD (Compact Disc) (Linto Herlambang, Moch.; Catur L, Azis, 2008).

\section{METODE PENELITIAN}

\section{Perencanaan Skenario Penelitian}

Skenario dari penelitan ini yaitu akan dibangun suatu jaringan dimana client mempunyai dua buah gateway. Dua gateway tersebut mempunyai bandwidth yang berbeda. Agar kedua gateway tersebut dapat digunakan bersama maka perlu diterapkannya metode load balancing yang secara teori dapat menyeimbangkan beban lalu lintas data pada kedua gateway dan menyedikan fungsi fail over.

Pada kedua metode load balancing akan dilakukan aktivitas yang menggunakan protocol TCP (Transmission Control Protocol), UDP (User Datagram Protocol maupun ICMP (Internet Control Message Protocol. Untuk melakukan hal ini akan digunakan Iperf yang mempunyai fungsi sebagai network packet generator dan juga analyzer, dan juga Ping serta Traceroute. Lalu lintas data yang melewati kedua load balancer akan di analisis hasilnya untuk dibandingkan satu sama lain. Parameter kinerja yang diuji adalah troughput, RTT, jitter dan packet loss.

Untuk menghemat sumber daya maka penelitian ini dilakukan dalam lingkungan virtual machine. Dalam virtual machine tersebut akan dibangun server, yang terkoneksi dengan client melalui beberapa 
router untuk mensimulasikan jaringan internet.

\section{Perancangan Topologi}

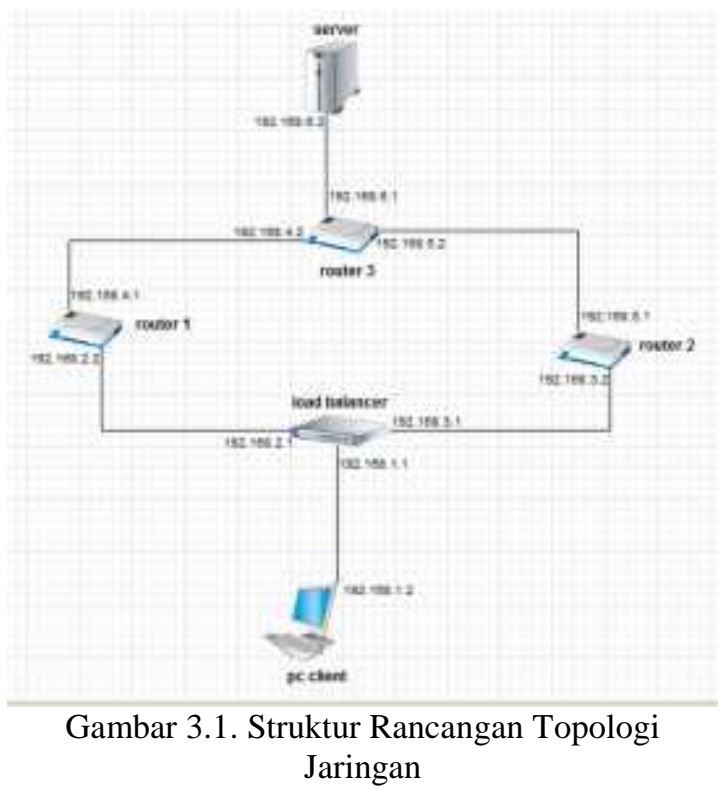

Seperti yang sudah dijelaskan dalam perancangan skenario, pada penelitian ini akan dibangun jaringan komputer di dalam virtual machine yang terdiri dari satu client, satu load balancer, dua gateway, satu router dan satu server. pada gambar 3.1, router 1 dan router 2 berfungsi sebagai gateway 1 dan gateway 2. Pada load balancer akan diterapkan metode PCC dan ECMP secara bergantian. Load balancer menyeimbangkan lalu lintas data dari kedua gateway menuju komputer client. Router 3 menghubungkan gateway ke server.

\section{Implementasi}

Jurnal Ilmiah "Technologia"
Setelah rancangan dari topologi jaringan dan semua kebutuhan sistem telah tersedia, maka langkah selanjutnya adalah implementasi dari penelitian ini.

Berikut ini adalah langkahlangkah implementasi pembangunan jaringan yang sesuai dengan topologi yang telah dirancang :

\section{a. Instalasi virtual machine \\ Virtual machine diinstal pada komputer host yang digunakan untuk melakukan penelitian.}

\section{b. Persiapan jaringan komputer pada virtual machine}

Persiapan ini meliputi:

- Instalasi sistem operasi masing-masing komputer baik client, load balancer, router maupun server,

- Instalasi sistem MikroTik RouterOS pada load balancer dan pada router,

- Serta konfigurasi jaringan komputer sampai semua sistem saling terhubung.

\section{c.Pengaturan konfigurasi load balancing PCC dan ECMP}

Pada tahap ini akan dilakukan konfigurasi pada masing-masing load balancer .

\section{d. Pengujian}

Pengujian dilakukan dengan berbagai cara melakukan aktivitas request dari client ke server melalui protocol TCP maupun UDP menggunakan aplikasi network analyzer yang telah ditentukan.

Setiap parameter quality of service diuji satu demi satu.

- Throughput

Pengujian throughput dilakukan dengan menggunakan tool iperf dengan modus TCP yang dilakukan selama 30 (tiga puluh) detik dan dilaporkan setiap detik.

- Packet loss

Pengujian packet loss dilakukan dengan menggunakan tool iperf dengan modus UDP, dengan cara melakukan 
pengujian sebanyak 6 (enam) kali kemudian diambil rata-rata packet loss nya.

- Jitter

Pengujian jitter dilakukan dengan menggunakan tool iperf dengan modus UDP, dengan cara melakukan pengujian sebanyak 6 (enam) kali kemudian diambil rata-rata jitter nya..

- RTT

Pengujian RTT dilakukan dengan menggunakan tool ping, dengan cara melakukan pengujian sebanyak 6 (enam) kali kemudian diambil rata-rata RTT nya.

\section{e. Analisis hasil pengujian}

Analisis hasil pengujian dilakukan dengan cara membandingkan data-data yang dihasilkan kedua metode load balancing pada saat pengujian sebelumnya pada setiap parameter kualitas layanan.

\section{HASIL DAN PEMBAHASAN}

\section{Hasil Pengujian}

Dari pengujian yang sudah dilakukan telah didapatkan hasil sebagai berikut:

\section{a. Pengukuran nilai throughput}

Berikut ini adalah hasil pengukuran nilai throughput pada masing-masing load balancing, dimana pengujian dilakukan selama tiga puluh detik dan dilaporkan setiap detik.

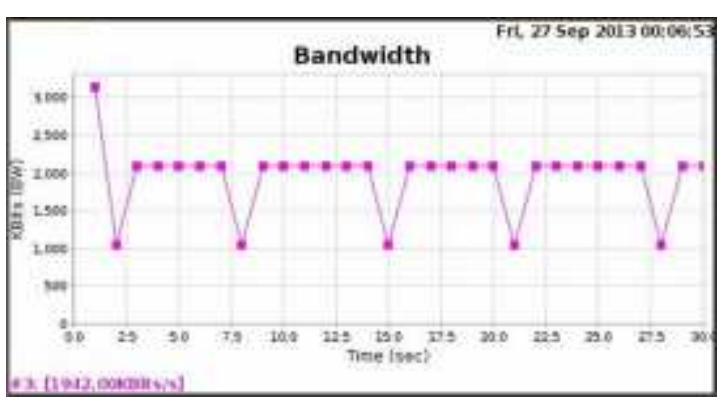

Gambar 4.1. Grafik Hasil Throughput pada ECMP

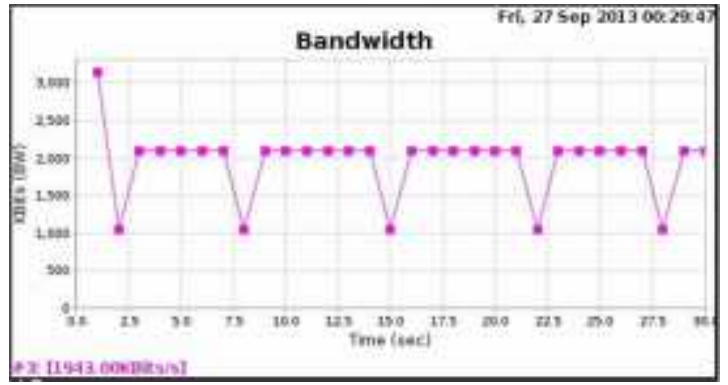

Gambar 4.2. Grafik Hasil Throughput pada PCC

Dari Gambar 4.1 metode ECMP dapat diketahui bahwa throughput berkisar antara $2000 \mathrm{Kbits} / \mathrm{s}$ sampai dengan 1000 Kbits/s, dengan rata-rata 1942 Kbits/s. Sedangkan pada paga Gambar 4.2 metode PCC, meskipun kisaran throughput hampir sama dengan pada metode ECMP, namun rata-rata throughput yang dihasilkan ternyata sedikit lebih tinggi yaitu pada 1943 Kbits/s.

b. Pengukuran nilai jitter.

\begin{tabular}{|c|c|c|c|c|c|c|c|}
\hline $\begin{array}{c}\text { Not } \\
\text { Jitter } \\
\text { (ms) }\end{array}$ & 2,029 & 1,929 & 1,827 & 2,594 & 2,298 & 1,948 & 2.104 \\
\hline
\end{tabular}

Gambar 4.3. Hasil Pengukuran Nilai Jitter Metode ECMP

\begin{tabular}{|c|c|c|c|c|c|c|c|}
\hline$\gamma_{n+1}$ & 1 & II & III & $\mathrm{N}$ & $\mathrm{v}$ & vI & Rata-ratia \\
\hline $\begin{array}{l}\text { Iitter } \\
\text { (Ims) }\end{array}$ & 2,500 & 1,925 & 2,104 & 2,437 & 2,047 & 3,069 & 2,339 \\
\hline
\end{tabular}

Gambar 4.4. Hasil Pengukuran Nilai Jitter Metode PCC

Pengujian dilakukan sebanyak 6 (enam) kali. Kemudian dicari nilai ratarata jitter yang dihasilkan. Dari Gambar 4.3 metode ECMP, Rata-rata yang didapatkan dari pengujian jitter adalah 2,104 ms. Sedangkan pada paga Gambar 4.4 metode PCC, rata-rata jitter yang dihasilkan adalah $\mathbf{2 , 3 3 9}$ ms.

c. Pengukuran nilai packet loss

\begin{tabular}{|c|c|c|c|c|c|c|c|}
\hline$\ldots+\infty$ & I & II & II & IV & V & VI & Rata-rata \\
\hline $\begin{array}{c}\text { PkL. Iass } \\
(\%)\end{array}$ & 0,47 & 0,47 & 0,59 & 0,47 & 0,47 & 0,47 & 0,49 \\
\hline
\end{tabular}


Gambar 4.5. Hasil Pengukuran Nilai Packet Loss Metode ECMP

\begin{tabular}{|c|cc|c|c|c|c|c|}
\hline $\begin{array}{c}\text { Now } \\
\text { ati }\end{array}$ & I & II & III & IV & V & VI & Rata-rata \\
\hline $\begin{array}{c}\text { Pkt, Lass } \\
(\%)\end{array}$ & 0,47 & 0,47 & 0,47 & 0,47 & 0,47 & 0,47 & 0.47 \\
\hline
\end{tabular}

Gambar 4.6. Hasil Pengukuran Nilai Packet Loss Metode PCC

Dari Gambar 4.5, didapatkan rata-rata packet loss pada jaringan yang menggunakan metode ECMP adalah $\mathbf{0 , 4 9 \%}$. Sedangkan pada paga Gambar 4.6 metode PCC, menghasilkan rata-rat packet loss sebesar $\mathbf{0 , 4 7 \%}$.

d. Pengukuran nilai RTT

\begin{tabular}{|c|c|c|c|c|c|c|c|c|c|}
\hline \multirow[t]{2}{*}{ test } & \multirow[t]{2}{*}{ Paket } & \multicolumn{4}{|c|}{ RTT pada ECMP (ma) } & \multicolumn{4}{|c|}{ RTT pada PCC (win) } \\
\hline & & Min & Avz & PfaI & Mdev & Mfia & $\boldsymbol{A} \mathrm{Vg}$ & Max & Mdev \\
\hline$T$ & 30 & 1.543 & 2,435 & 3,333 & 6,481 & 2,097 & 2,623 & 5,328 & 0.90 \\
\hline II & 30 & 1,760 & 2387 & 3,203 & 0,346 & 1,827 & 2,275 & 3,202 & $0,5,2$ \\
\hline III & 30 & 1927 & 2569 & 6,473 & 1,378 & 1913 & 5,045 & 11.896 & 3,357 \\
\hline$\pi$ & 30 & 1956 & 2278 & 2,928 & 0,293 & 1,999 & 2,872 & 6991 & 1,433 \\
\hline $\mathrm{V}$ & 30 & 1926 & 3,629 & 7,409 & 2056 & 1,854 & 2,263 & 2956 & 6313 \\
\hline VI & 30 & 2,006 & $2,4 \pi$ & 2,863 & 0.265 & 1.572 & 2,372 & 4098 & 0,521 \\
\hline $\begin{array}{l}\text { Rata } \\
\text { rata }\end{array}$ & & 1,903 & $2,2 \times 3$ & 4,308 & 0,799 & 1,854 & 2,908 & 5.745 & 1,173 \\
\hline
\end{tabular}

Hasil pengujian RTT menghasilkan RTT sebesar $\mathbf{2 , 2 8 3} \mathbf{m s}$ pada metode ECMP, dan 2,908 ms pada metode PCC.

\section{KESIMPULAN}

Berdasarkan hasil dari penelitian yang telah dilakukan, dapat ditarik kesimpulan yang memuat kelebihan dan kekurangan dari masing-masing metode load balancing. Kesimpulan tersebut adalah sebagai berikut :

1. Metode PCC menghasilkan throughput lebih baik daripada metode ECMP.

2. Metode PCC memiliki ketahanan atau reliabilitas yang lebih baik ketika terjadi gangguan pada jaringan.

3. Metode ECMP menghasilkan RTT yang lebih baik daripada metode PCC.
4. Perbandingan nilai jitter dan packet loss pada kedua metode load balancing tidak signifikan perbedaannya. Selain itu tingkat degradasi pada keduanya masih dapat ditoleransi dan termasuk dalam kategori sangat bagus.

\section{DAFTAR PUSTAKA}

Akbar, S., (2009), Penelitian Tindakan

Kelas : filosofi, metodologi \&

Implementasi, Yogyakarta: Cipta Media

Aksara.

Istijanto., (2005), Riset SDM, Cara

Praktis Mendeteksi Dimensi-Dimensi

Kerja Karyawan, Jakarta: PT. Gramedia

Pustaka Utama.

Linto Herlambang, Moch.; Catur L, Azis, (2008), Panduan Lengkap Menguasai

Router Masa Depan Menggunakan

MkroTik RouterOS, Yogyakarta: Andi

Offset.

Popek, Gerald J; Goldberg, Robert P., (1974), Formal Requirements for

Virtualizable Third Generation

Architectures, New York: Association for Computing Machinery.

Disastra, I., (2010), Perbandingan

Kinerja dan Keamanan PC Router Zebra dan Mikrotik RouterOS, Skripsi, FTI, UII, Yogyakarta.

Wulandari, S.; Affandi, A., (2011), Pengukuran Kinerja Layanan Jaringan Komputer Untuk Manajemen

Kertersediaan, SESINDO, (p. 2),

Surabaya.

Institut Teknologi Telkom, (2009), QoS dan Pengukurannya, In Diktat Telkom (p. 312), Bandung. 
Rizaldi, H.; dkk., (2010), Qos (Quality of Service), Makalah, FST, UINSK, Yogyakarta.

International Telecomunication Union, (2008), One Way Transmission Time,

Tersedia di http://www.cisco.com/en/US/tech/tk652/t k698/technologies_white_paper09186a00 800a8993.shtml.

Hopps, C., (2000), Analysis of an EqualCost Multi-Path Algorithm. Tersedia di http://tools.ietf.org/html/rfc2992.

MikroTik, (2008), Manual: PCC, Tersedia di http://wiki.mikrotik.com/wiki/Manual:PC C.

IEEE Communication Society, (1998), Network Reliability, Tersedia di
http://committees.comsoc.org/cqr/FAE_D ocs/B1_Net_Rel/nw4reliab.html.

Rouse, M., (2007), Round Trip Time (RTT), Tersedia di http://searchnetworking.techtarget.com/de finition/round-trip-time.

Blair, E., (2006), Latency, Tersedia di http://searchcio-

midmarket.techtarget.com/definition/laten cy.

Dewobroto, P., (2012), Load Balance Menggunakan Metode PCC, Tersedia di http://www.mikrotik.co.id/artikel_lihat.ph $\mathrm{p} ? \mathrm{id}=34$. 